\title{
Penerapan Metodologi Tozer Dalam Perencanaan Strategis Sistem Informasi Pada PT Telekomunikasi Indonesia Tbk Witel Bandung
}

\author{
Valentina Risky Budi Prawestri' ${ }^{1}$ Agustinus Fritz Wijaya² \\ 1,2Program Studi Sistem Informasi, Universitas Kristen Satya Wacana, Salatiga, Indonesia \\ Email:1682017079@student.uksw.edu, 2agustinus.wijaya@uksw.edu
}

\begin{abstract}
Strategic planning of information systems is one of the keys in achieving the target expected by an organization. With interviews, observations, and document studies, this study aims to 1) evaluate strategic planning based on strengths, weaknesses, opportunities and threats in improving quality at PT. Telekomunikasi Indonesia Tbk, Witel Bandung to find strategic information sisem 2) develop strategically using Tozer method with SWOT Analysis analysis (strength, weakness, opportunities, threats), Value Chain Porter, CSF Analysis (Critical Success Factor), McFarlan Grid's Portfolio Application Analysis, PEST Analysis. The final result of this research in the form of strategic planning recommendations of information systems will be useful to improve the information system in PT. Telecommunications Indonesia Tbk, Witel Bandung.
\end{abstract}

Keywords: Information System Strategy Planning, Tozer Methodology, Value Chain Analysis

\section{PENDAHULUAN}

Perkembangan teknologi yang semakin pesat pada era globalisasi sangat membantu untuk pengelolaan sebuah informasi (SI). Menurut Laudon dari Widyaningsih P (2011), sistem informasi adalah hubungan antara manusia, prosedur dan penggunaan teknologi untuk mengumpulkan, memproses, menyimpan, menyebarkan dan menyajikan informasi yang digunakan oleh satu atau lebih proses bisnis dalam organisasi. Sistem informasi adalah kombinasi dari sekelompok elemen terkait dengan pandangan untuk mengidentifikasi informasi yang diperlukan dan memastikan bahwa strategi sistem informasi selaras dengan strategi bisnis. Sistem informasi memiliki 
Vol. 1, No. 2, May 2020 e-ISSN: 2775-2496

https://journal-computing.org/index.php/journal-cisa/index

peran yang sangat penting dalam organisasi yaitu mendukung strategi bisnis organisasi untuk mendapatkan keunggulan kompetitif, sedangkan teknologi informasi (TI) adalah konvergensi antara teknologi komputer dan teknologi komunikasi yang menyebabkan sistem informasi dibangun dan berjalan sebagaimana mestinya karena dengan adanya teknologi suatu perusahaan, organisasi, instansi dapat meningkatkan efesien dan efektivitas kerja. Pembangunan teknologi informasi dan sistem informasi pada suatu perusahaan dilakukan secara bertahap, hal tersebut disesuaikan berdasarkan kekuatan dari sumber daya yang dimiliki oleh organisasi tersebut. Ada tiga sasaran utama dari upaya penerapan SI/TI dalam suatu organisasi. Pertama, memperbaiki efisiensi kerja dengan melakukan otomasi berbagai proses yang mengelola informasi. Kedua, meningkatkan keefektifan manajemen dengan memuaskan kebutuhan informasi guna pengambilan keputusan. Ketiga, memperbaiki daya saing atau meningkatkan keunggulan kompetitif organisasi dengan merubah gaya dan cara berbisnis (Ward and Peppard, 2002) [1]. Salah satu organisasi yang sudah menerapkan SI/TI adalah PT. Telekomunikasi Indonesia (Persero) Tbk (Telkom).

PT Telkom Indonesia (Persero) Tbk (Telkom) adalah Badan Usaha Milik Negara (BUMN) yang bergerak di bidang jasa layanan teknologi informasi dan komunikasi (TIK) dan jaringan telekomunikasi di Indonesia. Dalam upaya bertransformasi menjadi digital telecommunication company, TelkomGroup mengimplementasikan strategi bisnis dan operasional perusahaan yang berorientasi kepada pelanggan (customer-oriented). Transformasi tersebut akan membuat organisasi TelkomGroup menjadi lebih lean (ramping) dan agile (lincah) dalam beradaptasi dengan perubahan industri telekomunikasi yang berlangsung sangat cepat. Organisasi yang baru juga diharapkan dapat meningkatkan efisiensi dan efektivitas dalam menciptakan customer experience yang berkualitas. Kegiatan usaha TelkomGroup bertumbuh dan berubah seiring dengan perkembangan teknologi, informasi dan digitalisasi, namun masih dalam koridor industri telekomunikasi dan informasi. Hal ini terlihat dari lini bisnis yang terus berkembang melengkapi legacy yang sudah ada sebelumnya. Saat ini PT. Telekomunikasi Indonesia, Tbk Witel Bandung sudah menggunakan SI/TI yang sesuai dengan kebutuhan dan mendukung visi misi serta strategi bisinis namun belum maksimal. Berdasarkan hal tersebut maka diperlukan sebuah 
Vol. 1, No. 2, May 2020 e-ISSN: 2775-2496

https://journal-computing.org/index.php/journal-cisa/index

perencanaan strategis Sistem Informasi yang nantinya mampu menunjang kebutuhan SI/TI yang diperlukan. Agar suatu instansi dapat meningkatkan efesien dan efektivitas kerja salah satunya adalah dengan menggunakan perencanaan strategi sistem informasi yang baik.

Dengan adanya perencanaan strategi sistem informasi yang dibantu dengan TI, sebuah perusahaan dapat mengelola informasi dengan baik, cepat dan akurat. Penggunaan metode Tozer merupakan pilihan yang tepat dilihat dari kebutuhan kondisi bisnis PT. Telekomunikasi Indonesia Tbk, Witel Bandung saat ini. Model ini jelas dan sederhana dalam penyampaian strategi yang mempengaruhi kinejra peruahaan. Menurut Tozer arah pembuatan stratregi ini meliputi analisis faktor-faktor yang mempengaruhi kinerja peruahaan termasu lingkungan bisnis, memformulasikan strategi dengan metodologi yang tepat dengan bisnis yang ada, implementasi beberapa usulan dan proyek yang akan dijalankan, serta overwiew model dimana yang nantinya menggambarkan blok-blok dari formulasi strategi dan perencanaan serta aktivitas yang diperlukan [2].

\section{METODOLOGI PENELITIAN}

Dalam perencanaan strategis sistem infromasi, penggunaan metodologi merupakan suatu faktor yang penting. Metodologi perencanaan strategis sistem informasi yang digunakan dalam penelitian ini adalah metodologi Tozer. Adapun perangkat analisis yang digunakan: Analisis Strength, Weakness, Opportunities, Threats (SWOT), Rantai Nilai (Value Chain), Critical Success Factor (CSF), Application Portofolio McFarlan Grid's, PEST Analysis.

\subsection{Strength, Weakness, Opportunities, Threats (SWOT)}

Analisis SWOT adalah alat pengambilan keputusan untuk menentukan strategi yang dilakukan berdasarkan logika untuk memaksimalkan kekuatan dan peluang, tetapi secara bersamaan dapat meminimalkan kelemahan dan ancaman organisasi secara sistematis untuk merumuskan perencanaan strategis sistem informasi. Analisis ini dibagi menjadi dua, internal dan eksternal. Internal mencakup kekuatan dan kelemahan, sedangkan internal mencakup peluang dan ancaman. 


\section{Journal of Computer and Information Systems Ampera}

Vol. 1, No. 2, May 2020 e-ISSN: 2775-2496

https://journal-computing.org/index.php/journal-cisa/index

\begin{tabular}{|c|c|c|}
\hline & Strengths & Weakness \\
\hline हैँ & $\begin{array}{c}\text { ST } \\
\text { Memanfaatkan potensi untuk } \\
\text { menghadapi ancaman }\end{array}$ & $\begin{array}{c}\text { WT } \\
\text { Meminimalkan kelemahan } \\
\text { untuk menghadapi ancaman }\end{array}$ \\
\hline 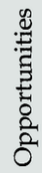 & $\begin{array}{c}\text { SO } \\
\text { Memanfaatkan potensi untuk } \\
\text { meraih peluang }\end{array}$ & $\begin{array}{c}\text { WO } \\
\text { Mengatasi kelemahan untuk } \\
\text { meraih peluang }\end{array}$ \\
\hline
\end{tabular}

Gambar 1. Analisis SWOT

\subsection{Analisis Rantai Nilai (Value Chain Porter)}

Value Chain (rantai nilai) adalah metode sistematis untuk memeriksa seluruh kegiatan organisasi dan untuk mengetahui interaksi yang digunakan organisasi sebagai sumber kegiatan bersaing seperti yang diungkapkan oleh Callon.

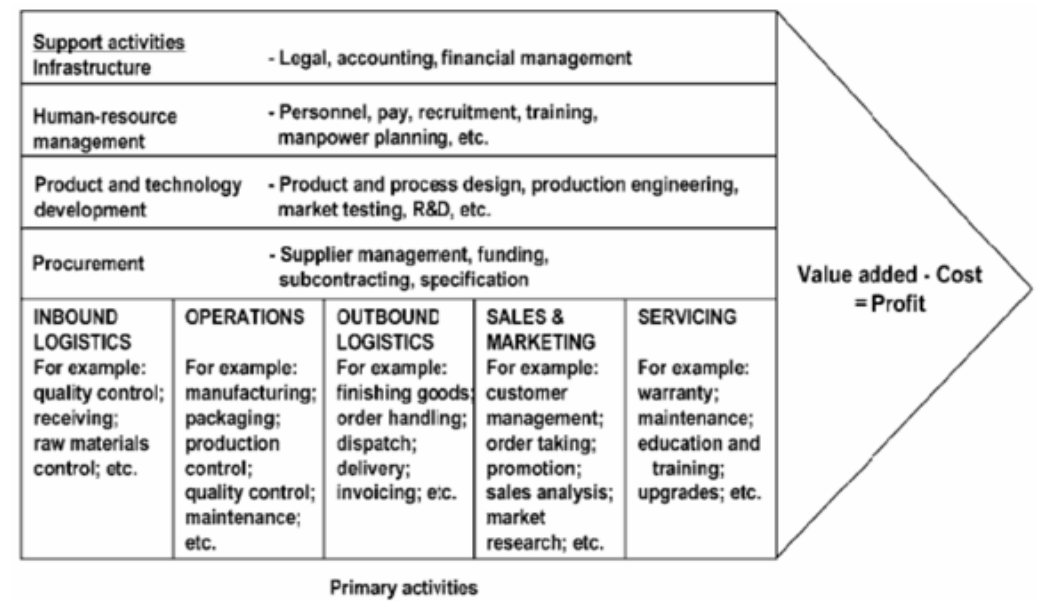

Gambar 2. Value Chain

\subsection{Critical Success Factor (CSF)}

Menurut Tozer, Critical Success Factor (CSF) merupakan suatu ketentuan dari organisasi dan lingkungannya yang berpengaruh pada keberhasilan atau kegagalan organisai. 
Vol. 1, No. 2, May 2020 e-ISSN: 2775-2496

https://journal-computing.org/index.php/journal-cisa/index

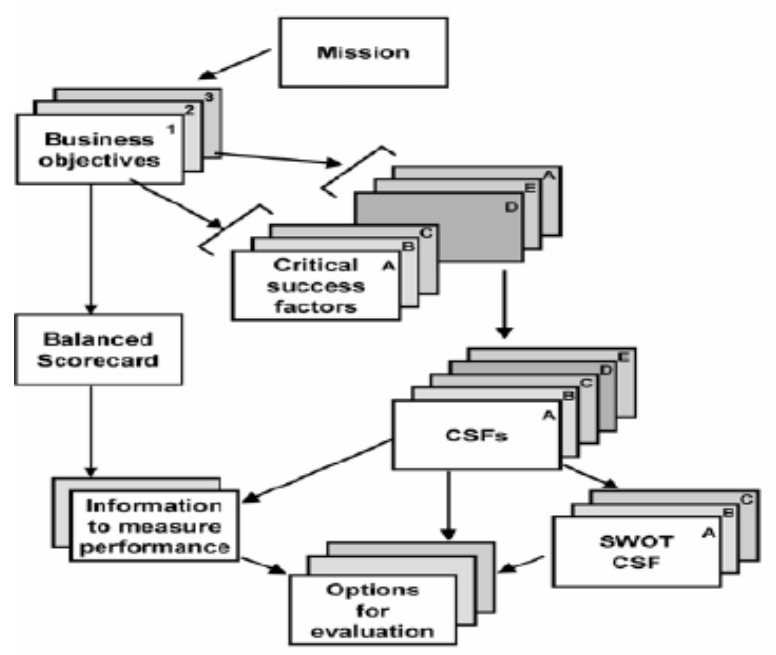

Gambar 3. Critical Success Factor (CSF)

\section{$2.4 \quad$ McFarlan Grid's}

McFarlan dan McKenney mengemukakan sebuah model untuk mengkategorikan sistem informasi kedalam empat golongan yaitu pendukung (support), High Potential, Key Operational dan Strategic.

\begin{tabular}{|l|l|}
\hline \multicolumn{1}{|c|}{ STRATEGIC } & \multicolumn{1}{|c|}{ HIGH POTENTIAL } \\
\hline $\begin{array}{l}\text { Aplikasi yang kritikal } \\
\text { untuk kelanjutan } \\
\text { strategi bisnis di masa } \\
\text { depan }\end{array}$ & $\begin{array}{l}\text { Aplikasi yang } \\
\text { mungkin penting } \\
\text { dalam mencapai } \\
\text { kesuksesan dimasa } \\
\text { depan }\end{array}$ \\
\hline - Aplikasi yang pada \\
$\begin{array}{l}\text { saat ini digunakan } \\
\text { perusahaan untuk } \\
\text { mencapai kesuksesan }\end{array}$ & $\begin{array}{l}\text { Aplikasi yang } \\
\text { berharga tapi tidak } \\
\text { kritikal untuk } \\
\text { kesuksesan }\end{array}$ \\
\hline KEY OPERATIONAL & \multicolumn{1}{|c|}{ SUPPORT } \\
\hline
\end{tabular}

\section{$2.5 \quad$ PEST Analysis}

Gambar 4. McFarlan Grid's

Analisis PEST (Politik, Ekonomi, Sosial dan Teknologi) menjelaskan kerangka dari faktor makro yang digunakan di lingkungan pemindaian komponen dari manajemen strategis. Analisis ini merupakan bagian dari analisis eksternal ketika melakukan analisis strategis atau pada saat riset pasar, dan 
memberikan gambaran yang berbeda terhadap faktor makro yang harus diambil dalam pertimbangan. Analisis ini adalah alat strategis untuk memahami pasar pertumbuhan atau penurunan, posisi, potensi dan arah untuk operasi. Dasar analisis PEST mencakup empat faktor:

1) Politik: faktor-faktor yang pada dasarnya adalah bagaimana campur tangan pemerintah dalam perekonomian. Secara khusus, faktor-faktor politik termasuk: kebijakan pajak, hukum perburuhan, hukum lingkungan, pembatasan perdagangan, tarif, dan stabilitas politik.

2) Ekonomi: faktor yang termasuk dalam aspek ini seperti: pertumbuhan ekonomi, suku bunga, nilai tukar, tingkat inflasi.

3) Sosial: faktor-faktor yang termasuk aspek budaya dan kesadaran kesehatan, laju pertumbuhan penduduk, distribusi usia, karier dan penekanan pada keselamatan.

4) Teknologi: faktor-faktor yang termasuk aspek teknologi seperti Penelitian dan Pengembangan, otomatisasi, insentif teknologi dan tingkat perubahan teknologi.

\subsection{Metodologi Tozer}

Dalam penggunaannya, metode tozer berlandaskan konsep strategi bisnis yang menentukan cara mengeksploitasi sumber daya SI dan TI beserta pemanfaatannya. Daur renstra SI versi Tozer terbagi sebagai berikut:

1. Fase 0 Pembuatan Konteks dan Batasan untuk Memulai Analisis

Tujuan fase ini memperoleh batasan, waktu, kontrol, penyelarasan terminologi, komitmen manajemen, dan harapan sistem. Produk yang dihasilkan analisis konteks, batasan, Term of Reference (TOR), identifikasi pendahuluan, tim kerja, program kerja, dan jadwal wawancara pendahuluan.

2. Fase 1 Penentuan Informasi Mengenai Bisnis dan Kebutuhan yang Mendukungnya Tujuannya membuat strategi seperti rencana ke depan dalam bentuk rencana bisnis, informasi, dan pendukung lainnya. Fase ini terbagi menjadi kegiatan persiapan pengumpulan informasi dan menentukan informasi bisnis beserta pendukungnya.

3. Fase 2 Membuat Arsitektur Informasi dan Pilihan Solusi

Pada fase ini terdapat empat kegiatan yaitu mengevaluasi aplikasi dan kondisi teknis saat ini, membangun arsitektur informasi, membuat pilihan 
Vol. 1, No. 2, May 2020 e-ISSN: 2775-2496

https://journal-computing.org/index.php/journal-cisa/index

awal untuk solusi strategi, dan membangun kasus bisnis untuk memenuhi kebutuhan bisnis.

4. Fase 3 Penentuan Solusi Strategis

Tujuan fase ini memperoleh dan memilih solusi strategis. Pada fase ini terdapat empat kegiatan yaitu identifikasi dan memulai kegiatan yang mendesak, menentukan solusi strategi, dan membangun kasus bisnis untuk memenuhi kebutuhan bisnis.

5. Fase 4 Menyiapkan dan Melakukan Rencana Implementasi

Tujuan dari fase ini adalah untuk menyelesaikan dan melaksanakan perencanaan strategis SI/TI, dimana terdapat beberapa kegiatan yaitu menyiapkan rencana teknis proyek aplikasi dan database, mempersiapkan rencana pengembangan SDM dan organisasi, menyusun dan menyeimbangkan kasus-kasus bisnis dengan semua pengembangan, dan menampilkan rencana dan implementasinya.

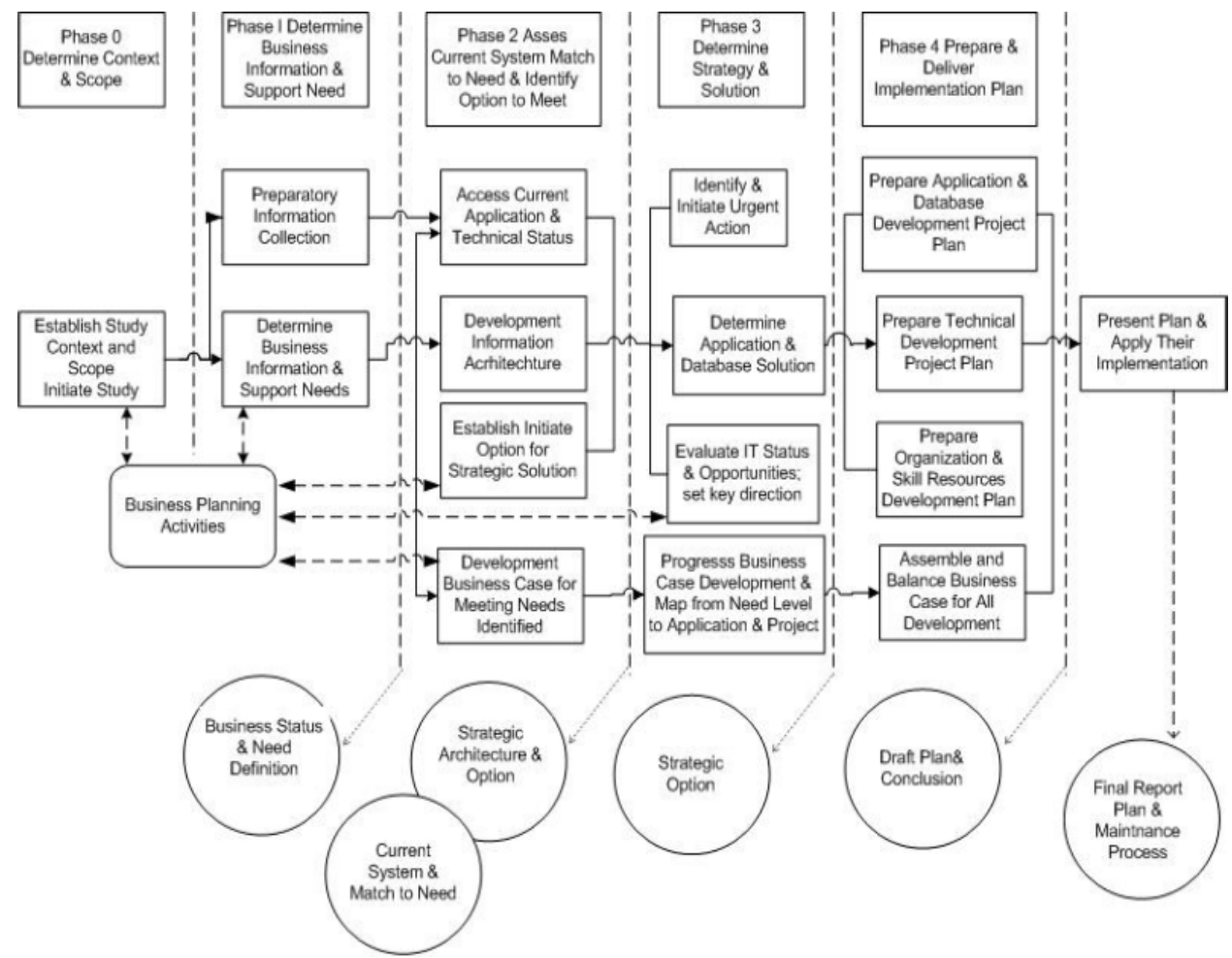

Gambar 6. Metodologi Tozer 


\section{Hasil dan Pembahasan}

Dengan adanya kerangka kerja perencanaan strategis SI/TI maka implementasi kerangka kerja untuk membuat perencanaan strategis SI/TI pada PT. Telekomunikasi Indonesia Tbk, Witel Bandung dapat dilakukan. Adapun tahapan kerangka kerja perencanaan strategis SI/TI adalah sebagai berikut:

\subsection{Fase 0 (Pembuatan Konteks dan Batasan untuk Memulai Analisis)}

a. Identifikasi Masalah

Berdasarkan pengamatan, PT. Telekomunikasi Indonesia Tbk, Witel Bandung memiliki masalah-masalah, seperti:

1. Pengawasan dalam pemasangan dan perbaikan produk masih kurang dan terbatas.

2. Penggunaan SI/TI sesuai dengan kebutuhan dan mendukung visi misi serta strategi bisinis yang belum maksimal.

b. Analisis Lingkungan Eksternal

Berdasarkan metode PEST, analisis lingkungan eksternal yang ada di PT.

Telekomunikasi Indonesia Tbk, Witel Bandung adalah:

1. Politik

- Gangguan stabilitas politik dan gejolak sosial atas isu-isu spesifik yang nantinya dapat berdampak negatif bagi bisnis, operasi, keadaan keuangan, hasil usaha, dan prospek serta harga pasar surat berharga.

2. Ekonomi

- Mengembangkan fasilitas TIK di berbagai layanan umum yang digunakan oleh masyarakat, serta dukungan terhadap usaha mikro dan menengah, terutama di sektor industri kreatif, terkait dengan optimalisasi pemanfaatan TIK.

- Perubahan aktivitas ekonomi global, regional ataupun di Indonesia yang berpengaruh pada bisnis, kondisi keuangan, hasil usaha maupun prospek usaha.

3. Sosial

- Mendukung pemberdayaan komunitas melalui edukasi tentang pemanfaatan TIK secara optimal untuk memudahkan aktivitas kehidupan masyarakat sehari-hari. 
https://journal-computing.org/index.php/journal-cisa/index

\section{Teknologi}

- Mengembangan, menyediakan, dan mengelola infrastuktur telekomunikasi dan beragam fasilitas teknologi informasi dan komunikasi (TIK) karena adanya tantangan di masa depan.

c. Analisis Lingkungan Internal

- Analisis SWOT

Tabel 1. Analisis SWOT

\begin{tabular}{|c|c|c|}
\hline & Strenght (S) & Weakness (W) \\
\hline Eksternal & $\begin{array}{l}\text { - Infrastruktur yang } \\
\text { dimiliki oleh } \\
\text { telkom sudah } \\
\text { menyeluruh dan } \\
\text { mencakup seluruh } \\
\text { wilayah tanah air } \\
\text { sehingga } \\
\text { perusahaan mudah } \\
\text { untuk melakukan } \\
\text { ekspansi dan } \\
\text { penetrasi pasar. }\end{array}$ & $\begin{array}{l}\text { - } \text { Bila ada pasang baru } \\
\text { dan perbaikan produk } \\
\text { masih dilakukan oleh } \\
\text { pihak ke-3 (anak } \\
\text { perusahaan telkom) } \\
\text { sehingga } \\
\text { pengawasaanya } \\
\text { kurang dan terbatas. }\end{array}$ \\
\hline Opportunity (0) & S-0 & W-0 \\
\hline $\begin{array}{l}\text { - Penduduk di } \\
\text { Indonesia yang } \\
\text { sudah } \\
\text { menggunakan } \\
\text { INDIHOME } \\
\text { (salah satu } \\
\text { produk } \\
\text { telkom) baru } \\
\text { mencapai } \\
\text { tujuh juta user } \\
\text { yang artinya } \\
\text { jumlah } \\
\text { pengguna akan } \\
\text { semakin } \\
\text { meningkat. } \\
\text { Pelayanan } \\
\text { terhadap } \\
\text { pelanggan }\end{array}$ & 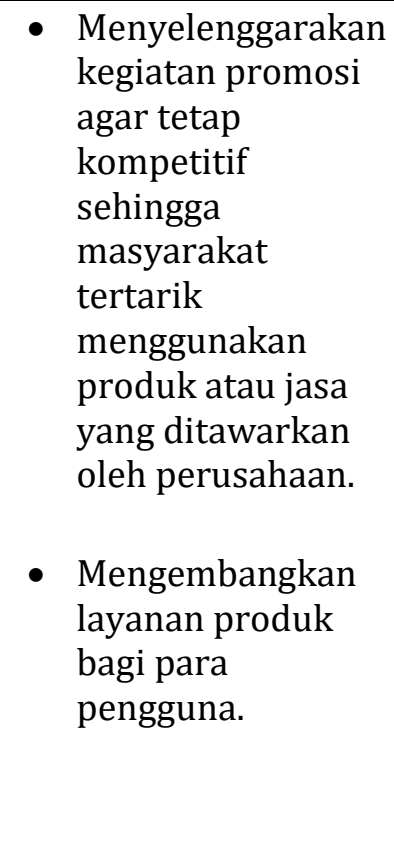 & 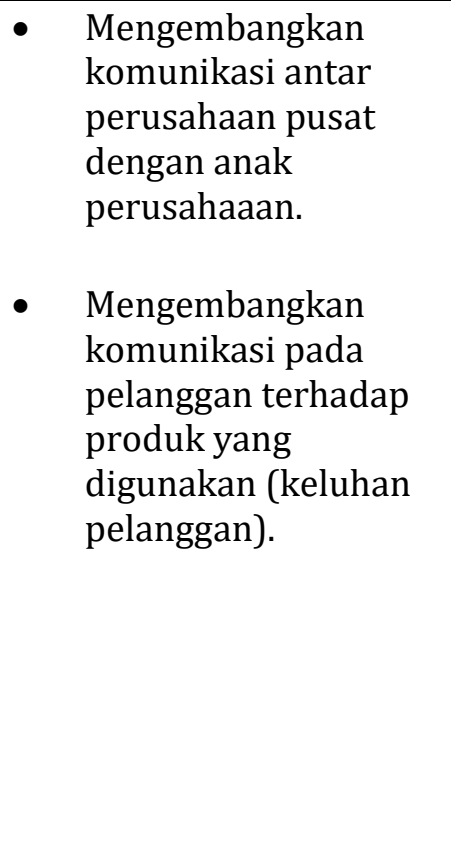 \\
\hline
\end{tabular}




\section{Journal of Computer and Information Systems Ampera}

Vol. 1, No. 2, May 2020 e-ISSN: 2775-2496

https://journal-computing.org/index.php/journal-cisa/index

\begin{tabular}{|c|c|c|}
\hline $\begin{array}{l}\text { sudah baik } \\
\text { dengan adanya } \\
\text { masa } \\
\text { pemeliharaan } \\
\text { dan service } \\
\text { garansi. }\end{array}$ & & \\
\hline Threat (T) & S-T & W-T \\
\hline $\begin{array}{l}\text { - Ancaman } \\
\text { keamanan fisik } \\
\text { dan cyber, } \\
\text { seperti } \\
\text { pencurian, } \\
\text { perusakan atau } \\
\text { tindakan lain. }\end{array}$ & $\begin{array}{l}\text { - Meningkatkan } \\
\text { pengawasan } \\
\text { koordinasi yang } \\
\text { intensif pada } \\
\text { pihak-pihak yang } \\
\text { terkait dengan } \\
\text { penanganan cyber } \\
\text { attack dan } \\
\text { melakukan } \\
\text { maintenance } \\
\text { secara berkala } \\
\text { terhadap } \\
\text { keamanan SI/TI di } \\
\text { tiap daerah. }\end{array}$ & $\begin{array}{l}\text { - } \text { Meningkatkan } \\
\text { kinerja SDM } \\
\text { perusahaaan dengan } \\
\text { cara memonitor dan } \\
\text { mengidentifikasi } \\
\text { semua jenis serangan } \\
\text { secara real time serta } \\
\text { memilih dan } \\
\text { melakukan tindakan } \\
\text { yang diperlukan } \\
\text { segera. }\end{array}$ \\
\hline
\end{tabular}

- Analisis Value Chain

\begin{tabular}{|c|c|}
\hline \multicolumn{2}{|c|}{ Adanya sistem pelaporan pelanggan } \\
\hline \multicolumn{2}{|c|}{ Melakukan quality control secara berkala } \\
\hline \multicolumn{2}{|c|}{ Melakukan pelatihan pada pegawai } \\
untuk meingkatkan kualitas
\end{tabular}

Gambar 7. Value Chain

Aktifitas utama dan aktivitas pendukung pada PT. Telekomunikasi Indoensia Tbk, Witel Bandung digambarkan melalui diagram value chain meliputi : 
1. Primary Activity
a. Melakukan kontrak kerja dengan mitra.
b. Melakukan pengawasan dan maintenance pada Infrastruktur TI.
c. Memasarkan produk.

2. Support Activity
a. Adanya sistem pelaporan pelanggan.
b. Melakukan quality control secara berkala.
c. Melakukan pelatihan pada developer untuk meningkatkan kualitas kinerja.
d. Penggunaan teknologi terbaru dalam pembangunan dan perkembangan sistem.

\subsection{Fase 1 (Penentuan Informasi Mengenai Bisnis dan Kebutuhan yang Mendukungnya)}

a. Identifikasi Informasi Bisnis

- Tujuan, visi dan misi:

Untuk menjawab tantangan industri digital, mendukung digitisasi nasional dan untuk menginternalisasi agenda transformasi, maka Telkom telah menajamkan kembali Purpose, Visi, dan Misi nya.

- Tujuan:

Mewujudkan bangsa yang lebih sejahtera dan berdaya saing serta memberikan nilai tambah yang terbaik bagi para pemangku kepentingan.

- Visi:

Menjadi digital telco pilihan utama untuk memajukan masyarakat

- Misi:

1. Mempercepat pembangunan Infrastruktur dan platform digital cerdas yang berkelanjutan, ekonomis, dan dapat diakses oleh seluruh masyarakat.

2. Mengembangkan talenta digital unggulan yang membantu mendorong keampuan digital dan tingkat adopsi sigital bangsa.

3. Mengorkestrasi ekosistem digital untuk memberikan pengalaman digital pelanggan terbaik.

b. Identifikasi Faktor Keberhasilan

Untuk menginetifikasi faktor-faktor apa saja yang bisa menentukan keberhasilan perusahaan bisa menggunakan analisa Critical Succes Factor 
Vol. 1, No. 2, May 2020 e-ISSN: 2775-2496

https://journal-computing.org/index.php/journal-cisa/index

(CSF). Berikut analisa CSF di PT. Telekomunikasi Indonesia Tbk, Witel Bandung:

- Critical Succes Factor (CSF).

Tabel 2. Critical Succes Factor (CSF)

\begin{tabular}{|l|l|}
\hline \multicolumn{1}{|c|}{ Tujuan Utama } & \multicolumn{1}{c|}{$\begin{array}{c}\text { Faktor Kunci Keberhasilan } \\
\text { (Critical Succes Factor) }\end{array}$} \\
\hline \multirow{4}{*}{$\begin{array}{l}\text { Menggunakan SI/TI yang } \\
\text { handal untuk mendukung } \\
\text { proses bisnis. }\end{array}$} & $\begin{array}{l}\text { Menerapkan pendekatan Competency } \\
\text { Based Human Resources Management } \\
\text { (CBHRM). Ada tiga model pendekatan, } \\
\text { yakni Specific Competency(Skill } \\
\text { Knowledge), Generic Competency (Personal } \\
\text { Quality), dan Core Competency (values). }\end{array}$ \\
\cline { 2 - 2 } & $\begin{array}{l}\text { Membuat semacam diretori di mana ada } \\
\text { daftar mengenai kompetensi yang } \\
\text { dibutuhkan. }\end{array}$ \\
\hline $\begin{array}{l}\text { Membangun kerjasama } \\
\text { dengan mitra bisnis sesuai } \\
\text { dengan standar informasi } \\
\text { yang sesuai dengan } \\
\text { spesifikasinya. }\end{array}$ & $\begin{array}{l}\text { Menjalin kerjama dengan Mitra Global dan } \\
\text { Lokal untuk mengakselerasi bisnis digital. }\end{array}$ \\
\hline
\end{tabular}

- Key Performance Indicator pada tabel adalah

1. Membangun SI/TI yang handal untuk mendukung prose bisnis.

2. Membangun kerjasama dengan mitra bisnis sesuai dengan standar informasi yang sesuai dengan spesifikasinya.

\section{a. Fase 2 (Membuat Arsitektur Informasi dan Pilihan Solusi)}

Analisis Sistem Infromasi dan Teknologi Informasi

1. Hardware

Tabel 3. Hardware

\begin{tabular}{|l|l|l|}
\hline Deskripsi & Detail & Satuan \\
\hline \multirow{4}{*}{ Hardware } & a. LCD Monitor 21 inch & Unit \\
\cline { 2 - 3 } & b. Komputer Server & Unit \\
\cline { 2 - 3 } & c. Switch / Hub Dlink 48 Port & Unit \\
\hline
\end{tabular}


Vol. 1, No. 2, May 2020 e-ISSN: 2775-2496

https://journal-computing.org/index.php/journal-cisa/index

\begin{tabular}{|l|l|l|}
\hline \multirow{7}{*}{} & d. UPS 1000 VA & Unit \\
\cline { 2 - 3 } & e. Kabel Belden & Roll \\
\cline { 2 - 3 } & f. Processor Dual Core 2 Ghz & Unit \\
\cline { 2 - 3 } & g. RAM 8GB & Unit \\
\cline { 2 - 3 } & h. Komputer Server & Unit \\
\cline { 2 - 3 } & i. Harddisk 1 TB (per PC) & Unit \\
\hline \multirow{4}{*}{ Perangkat } & Meja Komputer & Unit \\
\cline { 2 - 3 } & Rak server & Unit \\
\cline { 2 - 3 } & Kursi computer & Set \\
\cline { 2 - 3 } & AC Split 1 PK & Unit \\
\hline
\end{tabular}

2. Software

Tabel 4. Software

\begin{tabular}{|l|l|}
\hline $\begin{array}{l}\text { Digital } \\
\text { Business } \\
\text { Domain: }\end{array}$ & \\
\hline $\begin{array}{l}\text { Digital } \\
\text { Connectivity }\end{array}$ & $\begin{array}{l}\text { Fiber to the x (FTTx), 5G, Software Defined } \\
\text { Networking (SDN)/Network Function } \\
\text { Virtualization (NFV)/Satellite }\end{array}$ \\
\hline $\begin{array}{l}\text { Digital } \\
\text { Platform }\end{array}$ & $\begin{array}{l}\text { Data Center, Cloud, Internet of Things (IoT), Big } \\
\text { Data/Artificial Intelligence (AI), Cybersecurity }\end{array}$ \\
\hline $\begin{array}{l}\text { Digital } \\
\text { Services }\end{array}$ & Enterprise, Consumer \\
\hline
\end{tabular}

3. Mc Farlan Grid.s

Tabel 5. Mc Farlan Grid.s

\begin{tabular}{|c|c|}
\hline Strategic & High Potensial \\
\hline $\begin{array}{ll}\text { - } & \text { Manajemen SDM } \\
- & \text { Sistem Informasi } \\
& \text { Web Telkom }\end{array}$ & $\begin{array}{ll}\text { - } & \text { Aplikasi web } \\
\text { penilaian } \\
\text { pelayanan dari } \\
\text { pelanggan. }\end{array}$ \\
\hline $\begin{array}{l}\text { - Website resmi } \\
\text { produk }\end{array}$ & $\begin{array}{l}\text { - } \quad \text { Analisis kinerja } \\
\text { karyawan. }\end{array}$ \\
\hline Key Operatioanal & Support \\
\hline
\end{tabular}


Vol. 1, No. 2, May 2020 e-ISSN: 2775-2496

https://journal-computing.org/index.php/journal-cisa/index

\section{1) Fase 3 (Penentuan Solusi Strategis)}

Menentukan Solusi SI/TI berdasarkan value chain.

Tabel 6. Solusi SI/TI berdasarkan value chain

\begin{tabular}{|c|c|c|c|}
\hline Aktifitas & Value Chain & Kegiatan & SI/TI \\
\hline \multirow{5}{*}{ Primary } & Inbound Logistics & $\begin{array}{l}\text { Penyimpanan history } \\
\text { data teknis. }\end{array}$ & SIBORDER \\
\hline & Operation & $\begin{array}{l}\text { Pementauan } \\
\text { progress order. }\end{array}$ & SIBORDER \\
\hline & $\begin{array}{l}\text { Outbound } \\
\text { Logistics }\end{array}$ & $\begin{array}{l}\text { Mengeluarkan paket } \\
\text { internet terbaru } \\
\text { untuk pelanggan }\end{array}$ & $\begin{array}{l}\text { Indihome } \\
\text { Learning from } \\
\text { Home }\end{array}$ \\
\hline & $\begin{array}{l}\text { Marketing and } \\
\text { Sales }\end{array}$ & $\begin{array}{l}\text { Website resmi } \\
\text { produk }\end{array}$ & SI Produk \\
\hline & Service & $\begin{array}{l}\text { Penampungan } \\
\text { keluhan pelanggan. }\end{array}$ & SI Produk \\
\hline \multirow{4}{*}{ Support } & $\begin{array}{l}\text { Firm } \\
\text { Infrastructure }\end{array}$ & $\begin{array}{l}\text { Hubungan dengan } \\
\text { investor }\end{array}$ & $\begin{array}{l}\text { Website resmi } \\
\text { Telkom. }\end{array}$ \\
\hline & $\begin{array}{l}\text { Human Reource } \\
\text { Management }\end{array}$ & $\begin{array}{l}\text { Seleksi dan } \\
\text { penerimaan } \\
\text { pegawai. }\end{array}$ & $\begin{array}{l}\text { Website } \\
\text { reqruitment } \\
\text { Telkom. }\end{array}$ \\
\hline & $\begin{array}{l}\text { Technology } \\
\text { Development }\end{array}$ & $\begin{array}{l}\text { Memonitoring Base } \\
\text { Traciever Station } \\
\text { (BTS) }\end{array}$ & SIBRODER \\
\hline & Procurment & $\begin{array}{l}\text { Pengambilan } \\
\text { keputusan sesuai } \\
\text { data pelanggan. }\end{array}$ & $\begin{array}{l}\text { Website } \\
\text { clustering } \\
\text { pelanggan }\end{array}$ \\
\hline
\end{tabular}

a. Menentukan Solusi Strategi Aplikasi dan Database

Dilihat dari tren jaringan internet yang berada di pasaran saat ini dapat menentukan solusi aplikasi dan database yang banyak digunakan intansi maupun perusahaan. Berikut tren aplikasi dan database:

Tabel 7. Tren Jaringan Komputer

\begin{tabular}{|l|l|}
\hline Tren Jaringan Komputer & $\begin{array}{l}\text { 1. Internet } \\
2 . \text { Intranet }\end{array}$ \\
\hline
\end{tabular}


Vol. 1, No. 2, May 2020 e-ISSN: 2775-2496

https://journal-computing.org/index.php/journal-cisa/index

\begin{tabular}{|c|c|}
\hline & $\begin{array}{ll}\text { 3. } & \text { Wireless WIMAX } \\
\text { 4. } & \text { Kabel serat optik }\end{array}$ \\
\hline Tren aplikasi dan database & $\begin{array}{ll}1 . & \text { JAVA } \\
\text { 2. } & \text { PHP } \\
\text { 3. } & \text { ERP/SAP } \\
\text { 4. } & \text { SQL Server } \\
\text { 5. } & \text { My SQL } \\
\text { 6. } & \text { Oracle }\end{array}$ \\
\hline Tren pengamanan SI/TI & $\begin{array}{ll}\text { 1. } & \text { Autentikasi } \\
\text { 2. } & \text { Firewall } \\
\text { 3. } & \text { Enkripsi } \\
\text { 4. } & \text { Kebijakan pengamanan }\end{array}$ \\
\hline
\end{tabular}

\section{b. Analisis Kebutuhan Informasi}

Kebutuhan informasi pada PT. Telekomunikasi Indonesia Tbk, Witel Bandung dapat ditentukan berdasarkan analisa CSF yang kemudian diselaraskan dengan rumusan analisis SWOT dan value chain yang sudah dijabarkan pada analisis lingkungan internal bisnis organisasi.

Tabel 8. Analisis Kebutuhan Informasi

\begin{tabular}{|c|c|c|c|c|}
\hline $\begin{array}{l}\text { Strategi } \\
\text { Bisnis }\end{array}$ & Strategi SWOT & CSF & $\begin{array}{l}\text { Valune } \\
\text { Chain }\end{array}$ & $\begin{array}{l}\text { Kebutuhan } \\
\text { Informasi }\end{array}$ \\
\hline $\begin{array}{l}\text { Ekpansi } \\
\text { Global }\end{array}$ & $\begin{array}{l}\text { Menyelenggarak } \\
\text { an kegiatan } \\
\text { promosi agar } \\
\text { tetap kompetitif } \\
\text { sehingga } \\
\text { masyarakat } \\
\text { tertarik } \\
\text { menggunakan } \\
\text { produk atau jasa } \\
\text { yang ditawarkan } \\
\text { oleh } \\
\text { perusahaan. }\end{array}$ & $\begin{array}{l}\text { Membangun } \\
\text { kerjasama } \\
\text { dengan } \\
\text { mitra bisnis } \\
\text { sesuai } \\
\text { dengan } \\
\text { standar } \\
\text { informasi } \\
\text { yang sesuai } \\
\text { dengan } \\
\text { spesifikasiny } \\
\text { a. }\end{array}$ & $\begin{array}{l}\text { Marketin } \\
\text { g } \\
\text { And } \\
\text { Sales }\end{array}$ & $\begin{array}{l}\text { Laporan } \\
\text { mengenai } \\
\text { pembuatan } \\
\text { / } \\
\text { pembaharu } \\
\text { an dengan } \\
\text { mitra bisnis. }\end{array}$ \\
\hline
\end{tabular}


Vol. 1, No. 2, May 2020 e-ISSN: 2775-2496

https://journal-computing.org/index.php/journal-cisa/index

\begin{tabular}{|c|c|c|c|c|}
\hline \multirow{3}{*}{$\begin{array}{l}\text { Pengembang } \\
\text { an } \\
\text { Jaringan } \\
\text { Digital }\end{array}$} & $\begin{array}{l}\text { Mengembangka } \\
\text { n layanan } \\
\text { produk bagi } \\
\text { para pengguna }\end{array}$ & & $\begin{array}{l}\text { Techno- } \\
\text { Logical }\end{array}$ & \multirow{3}{*}{$\begin{array}{l}\text { Laporan } \\
\text { pengemban } \\
\text { g-an } \\
\text { mengenai } \\
\text { produk } \\
\text { yang sudah } \\
\text { ada. }\end{array}$} \\
\hline & $\begin{array}{l}\text { Mengembangka } \\
\mathrm{n} \text { komunikasi } \\
\text { antar } \\
\text { perusahaan } \\
\text { pusat dengan } \\
\text { anak } \\
\text { perusahaaan. }\end{array}$ & & $\begin{array}{l}\text { Develop- } \\
\text { ment }\end{array}$ & \\
\hline & $\begin{array}{l}\text { Mengembangka } \\
\mathrm{n} \text { komunikasi } \\
\text { pada pelanggan } \\
\text { terhadap produk } \\
\text { yang digunakan } \\
\text { (keluhan } \\
\text { pelanggan). }\end{array}$ & & Service & \\
\hline \multirow[t]{2}{*}{$\begin{array}{l}\text { Penguatan } \\
\text { Kinerja } \\
\text { Perusahaan }\end{array}$} & \begin{tabular}{|l} 
Meningkatkan \\
kinerja SDM \\
perusahaaan \\
dengan cara \\
memonitor dan \\
mengidentifikas \\
i semua jenis \\
serangan secara \\
real time serta \\
memilih dan \\
melakukan \\
tindakan yang \\
diperlukan \\
segera.
\end{tabular} & \multirow[t]{2}{*}{$\begin{array}{l}\text { Menggunaka } \\
\text { n SI/TI yang } \\
\text { handal } \\
\text { untuk } \\
\text { mendukung } \\
\text { proses } \\
\text { bisnis. }\end{array}$} & \multirow[t]{2}{*}{$\begin{array}{l}\text { Human } \\
\text { Resourc } \\
\text { e } \\
\text { Mana- } \\
\text { gement }\end{array}$} & $\begin{array}{l}\text { Laporan } \\
\text { diretori } \\
\text { mengenai } \\
\text { kompetensi } \\
\text { yang } \\
\text { dibutuhkan. }\end{array}$ \\
\hline & $\begin{array}{l}\text { Meningkatkan } \\
\text { pengawasan } \\
\text { koordinasi yang }\end{array}$ & & & $\begin{array}{l}\text { Laporan } \\
\text { jadwal }\end{array}$ \\
\hline
\end{tabular}


Vol. 1, No. 2, May 2020 e-ISSN: 2775-2496

https://journal-computing.org/index.php/journal-cisa/index

\begin{tabular}{|l|l|l|l|}
\hline intensif pada & & & pengawasa \\
pihak-pihak & & n dan \\
yang terkait & & & maintenanc \\
dengan & & e di setiap \\
penanganan & & & \\
cyber attack dan & & & \\
melakukan & & \\
maintenance & & \\
secara berkala & & & \\
terhadap & & \\
keamanan SI/TI & & & \\
di tiap daerah. & & & \\
\hline
\end{tabular}

2) Fase 4 (Menyiapkan dan Melakukan Rencana Implementasi)

a. Rencana Implementasi

Tabel 9. Rencana Implementasi

\begin{tabular}{|l|l|l|l|l|l|l|l|}
\hline \multicolumn{3}{|c|}{ Rekomendasi } & \multicolumn{5}{|c|}{ Tahun } \\
\hline No. & $\begin{array}{c}\text { Nama } \\
\text { Sistem } \\
\text { Infromasi }\end{array}$ & Penjelasan & 2021 & 2022 & 2023 & 2024 & 2025 \\
\hline 1. & $\begin{array}{l}\text { Aplikasi } \\
\text { laporan } \\
\text { jadwal } \\
\text { pengawasan } \\
\text { produk. }\end{array}$ & $\begin{array}{l}\text { Aplikasi ini } \\
\text { nantinya berisi } \\
\text { laporan jadwal } \\
\text { pengawasan } \\
\text { yang dilakukan } \\
\text { oleh anak } \\
\text { peruahaan } \\
\text { terhadap } \\
\text { produk pada } \\
\text { perusahaan } \\
\text { pusat guna } \\
\text { meminimalisir } \\
\text { terjadinya } \\
\text { kerusakan }\end{array}$ & & & & & \\
\hline
\end{tabular}


Vol. 1, No. 2, May 2020 e-ISSN: 2775-2496

https://journal-computing.org/index.php/journal-cisa/index

\begin{tabular}{|c|c|c|c|c|}
\hline 2. & $\begin{array}{l}\text { Aplikasi } \\
\text { penilaian } \\
\text { antar } \\
\text { pegawai }\end{array}$ & $\begin{array}{l}\text { Aplikasi ini } \\
\text { nantinya akan } \\
\text { digunakan } \\
\text { untuk } \\
\text { melakukan } \\
\text { penilaian } \\
\text { kinerja antar } \\
\text { pegawai sesuai } \\
\text { dengan } \\
\text { bidangnya } \\
\text { masing-masing } \\
\text { guna } \\
\text { meminimalisir } \\
\text { kinerja dari } \\
\text { pegawai yang } \\
\text { kurang efektif } \\
\text { dalam } \\
\text { melakukan } \\
\text { pekerjaanya } \\
\text { dan juga dapat } \\
\text { memotivasi } \\
\text { para pegawai } \\
\text { agar } \\
\text { meningkatkan } \\
\text { kualitas } \\
\text { kinerjanya. }\end{array}$ & & $\checkmark$ \\
\hline 3. & $\begin{array}{l}\text { Website } \\
\text { marketing } \\
\text { produk atau } \\
\text { layanan. }\end{array}$ & $\begin{array}{l}\text { Website yang } \\
\text { berisi } \\
\text { keunggulan } \\
\text { produk dan } \\
\text { keuntungan apa } \\
\text { saja yang akan } \\
\text { didapatkan oleh } \\
\text { calon pelanggan } \\
\text { jika }\end{array}$ & $\checkmark$ & \\
\hline
\end{tabular}




\section{Journal of Computer and Information Systems Ampera}

Vol. 1, No. 2, May 2020 e-ISSN: 2775-2496

https://journal-computing.org/index.php/journal-cisa/index

\begin{tabular}{|l|l|l|l|l|l|l|}
\hline & $\begin{array}{l}\text { menggunakan } \\
\text { produk atau } \\
\text { layanan dari } \\
\text { Telkom. }\end{array}$ & & & & & \\
\hline
\end{tabular}

b. Rencana Pengembangan

Tabel 10. Rencana Pengembangan

\begin{tabular}{|c|c|c|c|}
\hline $\begin{array}{c}\text { No. } \\
\text { Aktivitas }\end{array}$ & Aktifitas & Kebutuhan & PIC \\
\hline 1 & $\begin{array}{l}\text { Analisa dan Desain } \\
\text { Sistem }\end{array}$ & - Aplikasi & \\
\hline 1.1 & $\begin{array}{l}\text { Mengumpulkan data } \\
\text { harga bahan pangan }\end{array}$ & - Komputer & \\
\hline 1.2 & $\begin{array}{l}\text { Pembuatan Use Case } \\
\text { Diagram }\end{array}$ & $\begin{array}{ll}\text { - } & \text { Internet } \\
\text { - } & \text { Jasa sistem } \\
\text { analis }\end{array}$ & $\begin{array}{l}\text { System } \\
\text { Analyst }\end{array}$ \\
\hline 1.3 & $\begin{array}{l}\text { Pembuatan Activity } \\
\text { Diagram }\end{array}$ & & \\
\hline 1.4 & Pembuatan DFD & & \\
\hline 2 & Desain Aplikasi & - $\quad$ Komputer & \\
\hline 2.1 & $\begin{array}{l}\text { Membuat desain } \\
\text { Interface }\end{array}$ & - Jasa & UI Designer \\
\hline 2.2 & $\begin{array}{l}\text { Membuat desain layout } \\
\text { data }\end{array}$ & $\begin{array}{ll}\text { - } & \text { Aplikasi } \\
& \text { developer }\end{array}$ & \\
\hline 3 & Programming & $\begin{array}{ll}\text { - } & \text { Komputer } \\
\text { - } & \text { Jasa } \\
& \text { Progammer }\end{array}$ & Programmer \\
\hline 3.1 & Programming & & \\
\hline 4 & Testing Aplikasi & - $\quad$ Komputer & $\begin{array}{l}\text { Quality } \\
\text { Controller }\end{array}$ \\
\hline
\end{tabular}




\section{Journal of Computer and Information Systems Ampera}

Vol. 1, No. 2, May 2020 e-ISSN: 2775-2496

https://journal-computing.org/index.php/journal-cisa/index

\begin{tabular}{|c|c|c|c|}
\hline 4.1 & $\begin{array}{l}\text { Memberikan catatan list } \\
\text { perbaikan }\end{array}$ & - Internet & \\
\hline 5 & Implementasi & - Komputer & $\begin{array}{l}\text { Manager } \\
\text { Project }\end{array}$ \\
\hline 6 & Training User & & \multirow[t]{2}{*}{ Trainer } \\
\hline 6.1 & $\begin{array}{l}\text { Melakukan penyuluhan } \\
\text { ke user }\end{array}$ & & \\
\hline 7 & Maintenance & \multirow[t]{2}{*}{ - Komputer } & \multirow[b]{2}{*}{ Programmer } \\
\hline 7.1 & $\begin{array}{ll}\text { Pemeliharaan } & \text { dan } \\
\text { perbaikan sistem } & \end{array}$ & & \\
\hline 8 & Update Data & \multirow{2}{*}{$\begin{array}{l}\text { - Internet } \\
\text { - Komputer }\end{array}$} & \multirow[b]{2}{*}{ Surveyor } \\
\hline 8.1 & $\begin{array}{l}\text { Mengumpulkan kembali } \\
\text { data harga bahan pangan } \\
\text { secara berkala }\end{array}$ & & \\
\hline
\end{tabular}

\section{KESIMPULAN}

Berdasarkan hasil analisa yang diperoleh dalam penelitian ini menggambarkan bahwa sistem informasi yang dimiliki oleh PT Telekomunikasi Tbk, Witel Bandung sudah dapat mendukung proses bisnis perusahaan secara keseluruhan dan sudah baik adanya, hanya saja belum maksimal dan perlu untuk terus ditingkatkan lagi pada bagian pengawasan produk dan pada bagian kinerja karyawan. Peningkatan ini nantinya akan berguna untuk kelangsungan bisnis dan memnerikan nilai tambah bagi pelayanan perusahaan kepada konsumennya.

Saran untuk penelitian selanjutnya diharapkan untuk mengkaji lebih banyak sumber maupun referensi yang terkait dengan sistem informasi di PT Telekomunikasi Tbk, Witel Bandung agar penelitian ini nantinya bisa lebih baik lagi dan menganalisa metode-metode lebih mendalam kembali. 


\section{Daftar Pustaka}

[1] Adi Wiyono, Agustinus Fritz Wijaya, "perencanaan strategis sistem informasi di pt telekomunikasi indonesia, tbk witel semarang menggunakan ward and peppard", JBK, Vol. 2, No. 1, Februari 2020: 2332.

[2] Tri Hartati, "Perencanaan Master Plan Metodologi Tozer Pada Lembaga Pendidikan Teknologi Informasi Dan Komunikasi (Studi Kasus Pt Pesona Edu Solution Jakarta)", Jurnal Teknik dan Ilmu Komputer, Vol. 06 No. 22, Apr - Jun 2017.

[3] Windi Irmayani , "Perencanaan Strategis Si/Ti Pada Dinas Cipta Karya, Tata Ruang Dan Kebersihan Kabupaten Kubu Raya Dengan Menggunakan Metodologi Tozer", Journal Speed - Sentra Penelitian Engineering dan Edukasi - Volume 8 No 1 - 2016 - speed.web.id ISSN : 1979-9330 (Print) - 2088-0154 (Online) 59. 